\title{
Infective endocarditis: a survey of cases in the South-East Region of Scotland, 1969-72
}

\author{
R OGER H. SMITH, DOROTHY J.RA D F R D, \\ ROLANDA. CLARK, and DESMOND G. JULIAN
}

Cardiology Department, Royal Infirmary, Edinburgh

\begin{abstract}
Smith, R. H., Radford, Dorothy J., Clark, R. A., and Julian, D. G. (1976). Thorax, 31, 373-379. Infective endocarditis: a survey of cases in the South-East of Scotland from 1969-72. The incidence and characteristics of infective endocarditis were studied in a defined community over a four-year period.

Seventy-eight cases were found, giving an incidence of 16 cases per million per year. The commonest presenting features were those of infection; $53 \%$ had cardiac failure and $37 \%$ evidence of emboli when first seen. Twenty-three cases occurred on rheumatic heart valves, 13 on valvular prostheses, and 19 in previously normal hearts.

Streptococcus viridans was the commonest organism, but there was a relatively high incidence of staphylococcal infection. Only four cases were preceded by dental manipulation, and no source for the infection was found in 46 patients.

The mortality rate was $46 \%$, cardiac failure and embolic phenomena accounting for $65 \%$ of deaths. It is unlikely that earlier diagnosis or cardiac surgery would have reduced the mortality appreciably.
\end{abstract}

The pattern of infective endocarditis has altered considerably since Osler's classical description in 1909. This may be due to introduction of antibiotics, the declining incidence of rheumatic heart disease, and the development of cardiac surgery.

There has been little recent information regarding the pattern of the disease in the community, a point stressed by Weinstein and Rubin (1973). The present study of all the cases reported in what was formerly the South-East Region of Scotland from January 1969 to December 1972 attempts to determine the current position. This region included the City of Edinburgh, several industrial towns, a number of mining areas, and a large rural community with a total population of 1.2 million.

\section{METHODS}

From the computer record of the inpatient diagnostic index kept by the Scottish Home and Health Department details of all cases diagnosed as infective endocarditis in the region from January 1969 to December 1972 were obtained. Many known cases were missing from the computer record probably through inaccurate or inadequate coding. It was therefore supplemented in three ways:

1. The records of individual medical wards and specialized units where cases were likely to be admitted were scrutinized.

2. Consultants in the region were asked to give details of cases seen during the period.

3. Records of necropsies carried out during the survey period were inspected.

A questionnaire covering the main points to be surveyed was completed from each patient's case record.

\section{RESULTS}

INCIDENCE In the four years 78 cases were diagnosed, an incidence of 16 per million per annum.

Table I shows the clinical criteria for diagnosis. In $37(46 \%)$ the clinical diagnosis was confirmed by the pathological appearances at operation or necropsy.

Forty-eight were diagnosed in general medical units, 20 in cardiac, five in respiratory, four in infectious diseases, and one in thoracic surgical units. 
T A B L E I

DIAGNOSTIC FEATURES

\begin{tabular}{|c|c|c|c|}
\hline \multirow{2}{*}{ Clinical Features } & \multirow{2}{*}{$\begin{array}{l}\text { No. of } \\
\text { Cases }\end{array}$} & \multicolumn{2}{|c|}{$\begin{array}{l}\text { Post-mortem or } \\
\text { Surgical Evidence } \\
\text { of Endocarditis }\end{array}$} \\
\hline & & $\begin{array}{l}\text { No. of } \\
\text { Cases }\end{array}$ & $\%$ \\
\hline $\begin{array}{l}\text { Fever } \\
\text { Cardiac murmur } \\
\text { Positive blood culture }\end{array}$ & 34 & 11 & 32 \\
\hline $\begin{array}{l}\text { Fever } \\
\text { Cardiac murmur } \\
\text { Positive blood culture } \\
\text { Evidence of emboli }\end{array}$ & 21 & 14 & 66 \\
\hline $\begin{array}{l}\text { Fever } \\
\text { Cardiac murmur } \\
\text { Negative blood culture }\end{array}$ & 8 & 4 & 50 \\
\hline $\begin{array}{l}\text { Fever } \\
\text { Cardiac murmur } \\
\text { Negative blood culture } \\
\text { Positive serology }\end{array}$ & $\begin{array}{c}5 \\
\text { (3 with } \\
\text { evidence } \\
\text { of emboli) }\end{array}$ & 2 & 40 \\
\hline $\begin{array}{l}\text { Fever } \\
\text { Cardiac murmur } \\
\text { Negative blood culture } \\
\text { Evidence of emboli }\end{array}$ & 5 & 1 & 20 \\
\hline Post-mortem diagnosis only & $\begin{array}{c}5 \\
\text { (5 with } \\
\text { evidence } \\
\text { of emboli) }\end{array}$ & 5 & 100 \\
\hline
\end{tabular}

The Figure is a histogram of the age and sex distribution. The ages ranged from 15 to 88 years. There were 44 males and 34 females, a male to female ratio of $1 \cdot 3 / 1$. Males predominated under 50 , females in the next two decades, and thereafter there was no sex difference.

CLINICAL FINDINGS The main symptoms and signs at the time of admission to hospital are given in Tables II and III. The appearance of a cardiac murmur or a change in the character of an existing murmur during the illness was noted in 28 patients $(36 \%)$. In addition, 13 patients developed the features of cardiac failure and 12 evidence of embolism while in hospital.

PREDISPOSING CARDIAC LESIONS The cardiac lesions on which the endocarditis occurred are summarized in Table IV. In the patients thought to have involved normal valves, the state of the valve was confirmed at operation or necropsy in 12 .

In 71 patients it was probable that only the left side of the heart was involved. Right heart involvement was definite in three cases (two infected pacemakers and a patent ductus arteriosus) and possible in three (two with ventricular septal defects and one after surgical repair of tetralogy of Fallot). Right- and left-sided valvular lesions were confirmed at necropsy in one patient.

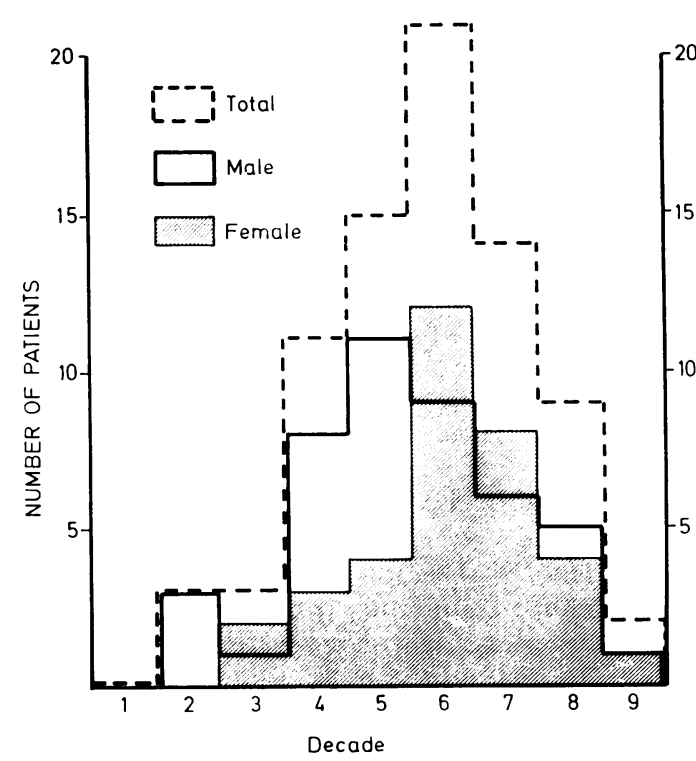

FIGURE Infective endocarditis 1969-72 age/sex dis कै tribution.

T A B L E I I

SYMPTOMS ON ADMISSION TO HOSPITAL

\begin{tabular}{|c|c|}
\hline Symptom & No. of Cases \\
\hline $\begin{array}{l}\text { Malaise, weakness } \\
\text { Fever, rigors, sweats } \\
\text { Dyspnoea, orthopnoea, ankle swelling } \\
\text { Symptoms of peripheral or pulmonary emboli } \\
\text { Symptoms of cerebral emboli } \\
\text { Arthralgia } \\
\text { Skin rash } \\
\text { Back pain }\end{array}$ & $\begin{array}{ll}65 & 83 \% \\
53 & 68 \% \\
36 & 46 \% \\
15 & 19 \% \\
14 & 18 \% \\
22 & 28 \% \\
15 & 19 \% \\
9 & 12 \%\end{array}$ \\
\hline
\end{tabular}

T A B L E I I I

CLINICAL FINDINGS ON ADMISSION

\begin{tabular}{|c|c|c|}
\hline Physical Signs & \multicolumn{2}{|c|}{ No. of Cases } \\
\hline $\begin{array}{l}\text { Pyrexia } \\
\text { Cardiac murmur } \\
\text { Signs of cardiac failure } \\
\text { Microscopic haematuria } \\
\text { Signs of arterial embolus } \\
\text { Finger clubbing } \\
\text { Splenomegaly } \\
\text { Rash or petechiae } \\
\text { Splinter haemorrhages } \\
\text { Subconjunctival haemorrhages } \\
\text { Osler's nodes }\end{array}$ & $\begin{array}{r}75 \\
63 \\
41 \\
36 \\
24 \\
21 \\
20 \\
20 \\
16 \\
7 \\
4\end{array}$ & $\begin{array}{l}96 \% \\
81 \% \\
53 \% \\
41 \% \\
31 \% \\
27 \% \\
26 \% \\
26 \% \\
21 \% \\
9 \% \\
5 \%\end{array}$ \\
\hline
\end{tabular}

뭉

BACTERIOLOGY In 56 cases $(72 \%)$ a positive bloo culture was obtained. The first culture was posid tive in 36 and in only five were more than six 
T A B LE I V

UNDERLYING CARDIAC LESIONS

\begin{tabular}{l|c|c}
\hline \multicolumn{1}{c|}{ Cardiac Lesion } & $\begin{array}{c}\text { No. of } \\
\text { Patients }\end{array}$ & $\begin{array}{c}\text { No. of } \\
\text { Deaths }\end{array}$ \\
\hline Rheumatic valvular disease & 23 & 9 \\
Non-rheumatic aortic valve disease & 16 & 5 \\
Prosthetic valve & 13 & 8 \\
Congenital heart disease & 5 & 1 \\
Implanted pacemaker & 2 & 1 \\
Normal heart & 19 & 13 \\
Total & 78 & 37 \\
\hline
\end{tabular}

cultures performed before a positive result was obtained. The mean number of cultures before a positive result was obtained was 2.59 (range 1-22). In cases where no positive result was obtained, the mean number performed was 8.9 (range 2-30). In five with negative blood cultures serological tests were positive, three for Coxiella burneti ( $\mathrm{Q}$ fever), one for staphylococcus, and one for streptococcus. The diagnosis of Coxiella endocarditis was based on raised complement fixation titres for both phase one and phase two antigens (Marmion et al., 1960). In a further two cases the infecting organism was cultured from vegetations taken at necropsy when the blood culture had been negative in life.

The frequency of isolation of each organism is given in Table $\mathrm{V}$. In 16 cases more than one organism was isolated. Where no organism was detected the majority $(65 \%)$ had received antibiotics before admission.

T A.B L E V

FREQUENCY OF ISOLATION OF EACH ORGANISM

\begin{tabular}{l|c|c}
\hline \multicolumn{1}{c|}{ Organism } & $\begin{array}{c}\text { No. of } \\
\text { Patients }\end{array}$ & $\begin{array}{c}\text { Average } \\
\text { Age (yr) }\end{array}$ \\
\hline Streptococcus viridans & 21 & 43 \\
Non-haemolytic streptococcus & 10 & 65 \\
Streptococcus faecalis & 5 & 53 \\
Staphylococcus aureus & 16 & 49 \\
Staphylococcus albus & 8 & 42 \\
Escherichia coli & 4 & 65 \\
Pneumococcus & 2 & 70 \\
Rickettsiae (Coxiella burneti) & 1 & 50 \\
Fungi (Candida) & 18 & 56 \\
No organism identified & & 54 \\
\hline
\end{tabular}

There was no clear relationship between the underlying cardiac abnormality and the type of infecting organism.

There was no indication of a possible source of the infection in 46 cases. Infective endocarditis was preceded by a respiratory tract infection in 11 patients, a skin infection in six, dental manipulation in four, a urinary tract infection in three, recent cardiac surgery in two, a bowel infection in two, and biliary colic, intravenous infusion, cardiac catheterization, and meningitis in one each.

The time from onset of symptoms to diagnosis in the whole series ranged from 1 to 300 days and averaged 55 days.

HAEMATOLOGY AND BIOCHEMISTRY A mild normocytic or hypochromic anaemia was found in $\mathbf{4 2}$ cases. A further three, all with prosthetic valves, had mild to moderate haemolytic anaemia. The remainder showed no evidence of anaemia. In 57 cases the ESR was greater than $40 \mathrm{~mm} / \mathrm{hr}$, in 15 above $100 \mathrm{~mm} / \mathrm{hr}$, and in four it was normal $(<10 \mathrm{~mm} / \mathrm{hr}$ ). The white cell count was normal throughout the course of the disease in hospital in 27 cases.

The blood urea was raised in 42 cases and the alkaline phosphatase in 25 , but in most cases the serum bilirubin and alanine aminotransferase levels were normal.

TREATMENT There was no standard regime of antibiotic therapy, the management remaining in the hands of the individual consultants. In the majority of patients a combination of antibiotics was used. In 22 cases the antibiotic regime was changed because of failure to respond clinically or as a result of sensitivity tests. The various combinations of antibiotic treatment are summarized in Table VI together with the mortalities for each regime.

\section{T A B L E V I} ANTIBIOTIC TREATMENT REGIMES

\begin{tabular}{|c|c|c|}
\hline Antibiotic Regime & $\begin{array}{c}\text { No. of } \\
\text { Cases }\end{array}$ & No. of Deaths \\
\hline $\begin{array}{l}\text { Penicillin and streptomycin } \\
\text { Antibiotic combination related } \\
\text { to the sensitivity of the organism } \\
\text { Repeated short course of } \\
\text { different antibiotics } \\
\text { No antibiotic given }\end{array}$ & $\begin{array}{r}29 \\
38 \\
6 \\
6\end{array}$ & $\begin{array}{rr}13 & 45 \% \\
14 & 37 \% \\
5 & 80 \% \\
6 & 100 \%\end{array}$ \\
\hline
\end{tabular}

Cardiac surgery was performed in 10 cases, in eight for replacement of damaged valves (for control of infection in six and to relieve cardiac failure in two), in one to close a persistent ductus arteriosus, and in one to remove an infected pacemaker. The operative mortality was $37 \%$. 
Anticoagulants were given to three patients while atrial arrhythmias were being controlled; in two the outcome was favourable while the third died with massive intracranial haemorrhage; these cases and our own views on the use of anticoagulants in infective endocarditis have been reported by Kanis (1974).

outcome In all, 37 patients died, a mortality rate of $46 \%$. Cardiac failure (10 cases), major embolic episodes (10 cases), and the combined effects of the two (4 cases) accounted for $65 \%$ of the deaths. In the remainder, death was attributed to acute renal failure ( 5 cases), intravascular coagulation ( 4 cases), operative mortality ( 3 cases), and rupture of the aorta (1 case).

DIAGNOSIS MADE POST MORTEM In five cases the diagnosis was made post mortem, having been missed in life. All had cardiac murmurs and mild pyrexia on admission to hospital: two had cerebral vascular accidents, one a major peripheral embolus, and one meningitis. Two had staphylococcal endocarditis, of whom one had infection on the wall of the left atrium but with normal valves, and the other, a chronic bronchitic, had an infected aortic valve. Two had coliform endocarditis of the mitral valve; one of these also had chronic myeloid leukaemia and the other diabetes mellitus with chronic renal failure. These four died within 18 days of the onset of the first symptom. The fifth patient had rheumatic heart disease with a year's history of recurrent skin ulcers, increasing cardiac failure, splenomegaly, and haematuria but negative blood culture on numerous occasions and was diagnosed as a connective tissue disorder.

\section{DISCUSSION}

This review is not directly comparable with any of the recently published series as it attempts to provide a community picture based on a survey of all traceable cases over a defined period.

There have been various estimates of the current incidence of infective endocarditis. Kaye et al. (1961) considered that the incidence had fallen in recent years. Lerner and Weinstein (1966) that it had increased, and Hayward (1973) that it was unchanged. Our incidence of 16 cases per million per annum is the first ever based on a population study.

The age distribution is similar to that reported by Lerner and Weinstein (1966) and Weinstein and Rubin (1973). There were no cases recorded in the first decade of life and only three in the $\overrightarrow{\vec{F}}$ second even though the region had a centre foro the investigation and surgical treatment of con-흠 genital heart disease.

Although there was a higher overall male inci- $\frac{\widehat{\Phi}}{\mathrm{Q}}$ dence in common with other reported series, there was not the clear male preponderance in the over ${ }^{\text {s }}$ 50 age group found by others (Lerner and Wein- $\vec{\circ}$ stein 1966; Weinstein and Rubin, 1973; Cherubin $\vec{\omega}$ and Neu, 1971; Hughes and Gauld, 1966; Pankey, ${ }^{\omega}$ 1961 and 1962).

The major presenting features were those of in- $\dot{x}$ fection, cardiac failure, and embolism.

On admissioin 36 patients had the symptoms and 41 the signs of cardiac failure while a further $\omega$ 13 cases developed failure during the course of응 their illness, giving an overall incidence of $70 \%$.

Evidence of emboli, peripheral or cerebral, was $\square$ found in 29 cases $(37 \%)$ on admission, which ise identical with that found by Cates and Christies (1951). Several of the younger patients developed $\overrightarrow{0}$ cerebral embolism, confirming the need to be alert to the possibility of infective endocarditis in these circumstances. The low incidence of fungalo endocarditis in this series is against the view that peripheral arterial embolism is particularly associ-ō ated with infections with these organisms (Lerner and Weinstein, 1966).

Lerner and Weinstein (1966) and Holler and $\overrightarrow{0}$ Pecora (1970) emphasized the importance of back 3 pain as a presenting symptom in endocarditis. Nine of our patients gave a clear history of back? pain as opposed to generalized aches and pain. In one of these cases a diagnosis of sacro-ileitis was 은 assumed. No case presented with the features of $\ddot{x}$ a prolapsed intervertebral disc, as was reported $\frac{O}{3}$ by Holler.

Flitting arthralgia was present in a quarter of the cases, but in no patient with rheumatic heart

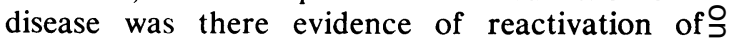
rheumatic fever, a feature reported as common $D$ by Matthew and Gilchrist (1949).

Eighty-one per cent of cases presented with aN cardiac murmur and a further $15 \%$ developed a murmur in hospital, which is similar to the findings of Lerner and Weinstein (1966). From a diagnostic point of view the demonstration of a? changing murmur or the appearance of a cardiaco murmur during the course of the disease is of the $\mathbb{D}$ greatest significance and occurred in $36 \%$ of the + cases. Oakley (1974) has argued that the develop- $\frac{T}{0}$ ment of, rather than a change in, the murmur is $\frac{\vec{D}}{\mathbb{D}}$ the hallmark of the disease.

Finger clubbing, splenomegaly, splinter haemor- $\stackrel{\mathbb{Q}}{\varrho}$ rhages, and Osler's nodes were relatively uncom- -0 
mon; Hayward (1973) and Oakley (1974) regarded these as features of long-standing endocarditis. The diagnostic value of splinter haemorrhages has been questioned by Gross and Tall (1963), who found them present in $19 \%$ of the normal population.

In spite of the current rarity of rheumatic fever in the United Kingdom (Ministry of Health and General Register Office, 1967) and the decline in the incidence of rheumatic heart disease, this was still the commonest underlying disease process in our series as in that of Lerner and Weinstein (1966).

Infection of a prosthetic valve was an important cause of endocarditis; mitral and aortic prostheses were equally involved. Only two of the 13 cases developed within three months of valve replacement so that it is unlikely that infection occurred at the time of surgery.

Although it is widely believed that infective endocarditis seldom occurs on normal valves, this was found in over $50 \%$ of Pankey's $(1961,1962)$ and Rabinovich's (1965) series, while in 1056 cases reviewed by Buchbinder there was an incidence of $26 \%$, similar to that in the present series.

In most series, infection of a normal valve has been associated with an acute course, involving virulent or unusual organisms, and a high mortality. In the present study, there was little bacteriological difference between cases with normal valves and other groups, and the average age was the same but there was a slightly higher mortality.

Both our cases with right heart lesions and normal valves had infected pacemakers. Cherubin et al. (1968) and Oakley (1974) have reported an increasing incidence of staphylococcal endocarditis involving normal right heart valves among heroin addicts in the United States. No case involving drug addiction was encountered in this study, which may reflect the low incidence of hard drug abuse in the region at the time of the survey.

In spite of a high incidence of staphylococcal infection around haemodialysis shunts, no cases of endocarditis were recorded in such patients, which contrasts with the findings of King et al. (1971).

In the group of cases referred to as non-rheumatic aortic valvular disease, those valves inspected at necropsy or surgery were bicuspid, sclerotic or calcified.

A striking feature was that, regardless of the basic cardiac abnormality, the bacteriological findings were broadly identical.

Where an organism was found a positive culture was usually obtained from the first six blood specimens. Attention has been drawn to the high incidence of previous antibiotic treatment in those cases with negative blood culture.

It is important to emphasize that if bacterial endocarditis is suspected and blood cultures are negative then Coxiella ( $Q$ fever) endocarditis should be considered. (Two other cases, with negative cultures, had raised antibody titres for staphylococcus and streptococcus respectively, suggesting recent infection, and both responded well to treatment with appropriate antibiotics.)

Streptococcus viridans was the commonest organism with the lowest mortality while infection with Staphylococcus aureus had the worst prognosis. Coliforms and the pneumococcus tended to be grown from older patients with generalized debility. Only one case of fungal endocarditis was traced and this occurred within three months of cardiac surgery. The low incidence of fungal endocarditis in this series may reflect the infrequency with which antibiotics were administered by intravenous infusion (only four cases).

Apart from the three cases of Coxiella endocarditis reported here, a further three cases were referred from outside the region during the study period but these are not included. All six cases have been reported as part of a larger series (Turck et al., 1976).

In only four cases was the infection related to dental manipulation and in none of these cases was the underlying cardiac lesion rheumatic heart disease. This may reflect the policy of giving antibiotic cover for dental procedure in these patients. No cases followed investigative cardiac catheterization; antibiotics were used to cover the investigation in one centre but not in another. There were no cases related to pregnancy and labour in patients with rheumatic heart disease, although it was the policy not to give antibiotics in these circumstances.

Apart from those submitted for surgery, a further eight patients had disturbances of cardiac function which might have benefited from cardiac surgery, but seven of these had had such complications as ischaemic heart disease, major peripheral emboli or gross toxaemia which were considered to contraindicate surgery. The eighth patient, with an infected aortic prosthetic valve, died from rupture of the aorta at the site of the valve attachment (Franklin and Jacques, 1974).

Surgery has a part to play in the management of infective endocarditis, usually to correct aortic or mitral regurgitation, sometimes to remove infected material. The operative mortality in this series was high and probably reflects the advanced stage of cardiac failure and the effects of severe 
infection. It should also be noted that surgical techniques and operative mortality have improved considerably since the period covered by the survey.

Oakley (1974) believed the mortality with modern antibiotic therapy to be about $30 \%$ while Weinstein and Rubin (1973) reported it to be less than $10 \%$. The mortality rate in this series was $46 \%$. The present study reflects the pattern in the community as a whole rather than the experience of a specialized unit. The mortality figures are not unduly weighted by the cases first diagnosed at necropsy.

Four of the five cases diagnosed at necropsy but not in life died of the effects of major arterial emboli within four days of admission to hospital. All had cardiac murmurs and were pyrexial but accurate diagnosis and treatment would probably not have altered the prognosis.

The fifth case illustrates the importance of not being misled by a series of negative blood cultures when bacterial endocarditis is strongly suspected. In both this and a further case in the series, a connective tissue disease was considered after blood cultures had been repeatedly negative and both patients given corticosteroids. In one case the outcome was fatal with a postmortem diagnosis, and in the other, Coxiella endocarditis was diagnosed after transfer to a cardiac unit where appropriate treatment was instituted and the patient survived. Both patients had positive serology for rheumatoid factor but this test is positive in $15-20 \%$ of infective endocarditis patients (Messner et al., 1968).

We thank the physicians and surgeons in the South East Region of Scotland who kindly allowed us access to their case records, and Dr. R. M. Marquis who was so helpful in his criticism of the manuscript.

\section{REFERENCES}

Cates, J. E. and Christie, R. V. (1951). Subacute bacterial endocarditis: a review of 442 patients treated in 14 centres appointed by the Penicillin Trials Committee of the Medical Research Council. Quarterly Journal of Medicine, 20, 93.

Cherubin, C. E., Baden, M., Kavaler, F., Lerner, S., and Cline, W. (1968). Infective endocarditis in narcotic addicts. Annals of Internal Medicine, 69, 1091.

Cherubin, C. E. and Neu, H. C. (1971). Infective endocarditis at the Presbyterian Hospital in New York City, 1938-1967. American Journal of Medicine, 51, 83.

Franklin, D. H. and Jacques, J. (1974). Pulmonary artery compression by haemorrhage from the

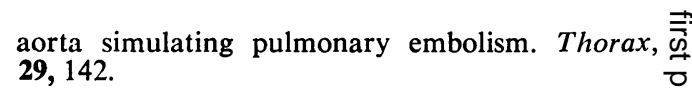

Gross, N. J. and Tall, R. (1963). Clinical significance 흠 of splinter haemorrhages. British Medical $\bar{\omega}$ Journal, 2, 1496.

Hayward, G. W. (1973). Infective endocarditis: a changing disease. British Medical Journal, 3, ๙ $706 ; 764$.

Holler, J. W. and Pecora, J. S. (1970). Backache in $\vec{\overrightarrow{ }}$ bacterial endocarditis. New York State Journal of Medicine, 70, 1903.

Hughes, P. and Gauld, W. R. (1966). Bacterial endocarditis: a changing disease. Quarterly $\underset{\sim}{\omega}$ Journal of Medicine, 35, 511.

Kanis, J. A. (1974). The use of anticoagulants in bacterial endocarditis. Postgraduate Medical $\omega$ Journal, 50, 312.

Kaye, D., McCormack, R. C., and Hook, E. W. (1961). Bacterial endocarditis: the changing pattern since the introduction of penicillin therapy. Anti-ce microbial Agents and Chemotherapy, pp. 37-46.

King, L. H. Jr., Bradley, K. P., Shires, D. L. Jr., $\overrightarrow{0}$ Donohue, J. P., and Glover, J. L. (1971). Bacterial endocarditis in chronic haemodialysis $\sigma$ patients: a complication more common than previously suspected. Surgery, 69, 554.

Lerner, P. I. and Weinstein, L. (1966). Infective endccarditis in the antibiotic era. New England Journal of Medicine, 274, 199, 259, 323, 388.

Marmion, B. P., Higgins, F. E., Bridges, J. B., and $\underset{\overrightarrow{1}}{\overrightarrow{2}}$ Edwards, A. T. (1960). A case of subacute rickettsial endocarditis: with a survey cf cardiac 3 patients for this infection. British Medical Journal, 2, 1264.

Matthew, H. and Gilchrist, A. R. (1949). Subacute bacterial endocarditis and its treatment with penicillin. Transactions of the Medico Chirurgical Society of Edinburgh. Edinburgh Medical Journal, 46, 25.

Messner, R. P., Laxdal, T., Quie, P. G., and Williams, R. C. Jr. (1968). Rheumatoid factors in subacute bacterial endocarditis-bacterium, duration of disease or genetic predisposition. Annals of윽 Internal Medicine, 68, 746.

Ministry of Health and General Register Office (1967). 을 Report on Hospital In-Patient Enquiry 1960 and 1961, Part III (Commentary), p. 89. HMSO, London.

Oakley, C. M. (1974). Infective endocarditis. British Journal of Hospital Medicine, 11, 101.

Osler, W. (1909). Chronic infective endocarditis. Quarterly Journal of Medicine, 2, 219.

Pankey, G. A. (1961). Subacute bacterial endocarditis at the University of Minnesota Hospital, $1939^{\circ}$ through 1959. Annals of Internal Medicine, 55, 550 .

Pankey, G. A. (1962). Acute bacterial endocarditis at $\frac{\stackrel{\Phi}{\Phi}}{\Phi}$ University of Minnesota Hospitals 1939-1959. ¿ American Heart Journal, 64, 583. 
Rabinovich, S., Evans, J., Smith, I. M., and January, L. E. (1965). A long-term view of bacterial endocarditis, 337 cases, 1924-1963. Annals of Internal Medicine, 63, 185.

Turck, W. P. G., Howitt, G., Turnberg, L. A., Fox, H., Longson, M., Matthews, M. B., and Das Gupta, R. (1976). Chronic Q fever. Quarterly Journal of Medicine, 45, 193.
Weinstein, L. and Rubin, R. H. (1973). Infection and the heart: infective endocarditis. Progress in Cardiovascular Diseases, 16, No. 3.

Requests for reprints to: Dr. R. H. Smith, Department of Cardiology, Western General Hespital, Crews Road, Edinburgh EH4 2XU. 